\title{
BAP E AIB NO CULTIVO IN VITRO DE Eugenia pyriformis Cambess
}

\section{$B A P$ and $A I B$ in vitro cultivation of Eugenia pyriformis Cambess}

\author{
Aline da Costa Nascimento ${ }^{a}$, Renato Paiva ${ }^{b}$, Raírys Cravo Nogueirac, \\ Jorge Marcelo Padovani Porto ${ }^{d}$, Gabriela Ferreira Nogueira ${ }^{e}$, Fernanda Pereira Soares ${ }^{f}$
}

${ }^{a}$ Bióloga, Mestranda em Agronomia/Fisiologia Vegetal, UFLA. Barbacena. MG - Brasil, e-mail: aline_costabq@yahoo.com.br ${ }^{\mathrm{b}}$ Engenheiro Agrônomo, Professor Adjunto do Departamento de Biologia, Setor de Fisiologia Vegetal, Universidade Federal de Lavras - UFLA. Lavras, MG - Brasil, e-mail: renpaiva@ufla.br

c Bióloga, Pós-Doutoranda, bolsista FAPEMIG, Departamento de Biologia, Setor de Fisiologia Vegetal, UFLA. Belém, PA Brasil, e-mail: rairys@yahoo.com.br

d Biólogo, Mestrando em Agronomia/Fisiologia Vegetal, Departamento de Biologia, Setor de Fisiologia Vegetal, UFLA. Lavras, MG - Brasil, e-mail: marcelo_pado@yahoo.com.br

e Graduanda em Biologia, bolsista de Iniciação Científica-FAPEMIG, Departamento de Biologia, Setor de Fisiologia Vegetal, UFLA.Lavras, MG - Brasil, e-mail: gabi_bioufla@hotmail.com

${ }^{f}$ Engenheira Agrônoma, Doutoranda em Fisiologia Vegetal, UFLA. Lavras, MG - Brasil, e-mail: fernandapereirasoares@yahoo.com.br

\section{Resumo}

A uvaieira (Eugenia pyriformis) é uma espécie arbórea nativa da Mata Atlântica pertencente à família Myrtaceae. O presente objetivou avaliar a influência dos reguladores de crescimento BAP e AIB na micropropagação de uvaieira. Para a indução de brotações foram utilizadas diferentes concentrações de BAP em segmentos nodais. Após a avaliação, aos 60 dias, as brotações obtidas in vitro foram transferidas para meio de cultura WPM, contendo $3 \%$ de sacarose, $0,5 \mathrm{~g} \mathrm{~L}^{-1}$ de carvão ativado e diferentes concentrações de AIB. Aos 40 dias, avaliou-se a porcentagem de enraizamento, o número e o comprimento da maior raiz. Para a aclimatização, as plantas foram transferidas diretamente ou após passarem por um período de sete dias de pré-aclimatização, para tubetes contendo Plantmax ${ }^{\circledR}$ e envoltas com saco plástico transparente para a manutenção da umidade. As sacolas de polietileno foram sendo perfuradas até a sua total remoção e, aos 31 dias, avaliou-se a taxa de sobrevivência das plântulas. A concentração de $1,0 \mathrm{mg} \mathrm{L}^{-1} \mathrm{BAP}$ proporciona melhores resultados na fase de multiplicação e o AIB, na concentração de $1,0 \mathrm{mg} \mathrm{L}^{-1}$, produz a maior porcentagem de formação de raízes em brotações originadas in vitro. O período de pré-aclimatização em sala de crescimento aumenta a proporção de sobrevivência de plântulas e a abertura gradual do saco plástico envoltório dos tubetes caracteriza um processo viável de aclimatização.

Palavras-chave: Brotações; Enraizamento; Aclimatização. 


\begin{abstract}
The "uvaieira" (Eugenia pyriformis) is a native tree specie from the Atlantic Forest, belonging to the Myrtaceae family. The present work has as objective to evaluate the influence of the $B A P$ and $A I B$ growth regulator in the "uvaieira" micro propagation. For the shoots induction, it was used different concentrations of BAP in nodal segments. After the evaluation at the $60^{\text {th }}$ day, the shoots obtained in vitro were transferred to WPM culture, having $3 \%$ of saccharose, $0.5 \mathrm{~g} . \mathrm{l}^{-1}$ of activated coal and different concentrations of AIB. After 40 days, the roots formation, the number and the length of the upper root were evaluated. For the acclimatization, the plants had been transferred directly, or after a seven days daily pre-acclimatization period, to tubule with Plantmax ${ }^{\circledR}$ and involved with transparent plastic bag, for the humidity maintenance. The polyethylene bags had been perforated until their total removal and, at the $31^{\text {th }}$ day, the survival rate of plants was evaluated. The $1.0 \mathrm{mg}$ of BAP per liter concentration provided better result in the multiplication phase and the AIB, in the same concentration, produces the highest percentage of root formation, to the shoots originated in vitro. The period of pre-acclimatization in growth room increases the survival rate of plants, and the gradual opening of the plastic bag of tubule is a viable acclimatization process.
\end{abstract}

Keywords: Shoots; Rooting; Acclimatization.

\title{
INTRODUÇÃO
}

Eugenia pyriformis Cambess é uma espécie arbórea nativa da Mata Atlântica, popularmente conhecida como uvaieira, podendo ser encontrada desde o estado de Minas Gerais até o Rio Grande do Sul. Mattos (1956) cita que a uvaia é uma espécie altamente valiosa pela sua madeira dura, resistente às doenças e, principalmente, por seus frutos comestíveis, nutricionalmente importante e apreciados pelo homem e pela avifauna. Seu plantio também é recomendado em casos de reflorestamentos heterogêneos (LORENZI, 2000).

Há dificuldades na produção de mudas de Eugenia pyriformis pela carência de sementes. $\mathrm{Na}$ literatura só foram encontrados registros de pomares experimentais, mas nenhum implantado para produção de sementes ou para produção comercial de frutos (SILVA et al., 2003). Além disso, o número de sementes por fruto é pequeno (MATTOS, 1956) e a dificuldade na produção de mudas é maior pela ausência de tecnologia que permita a maximização do processo. Sementes de várias espécies de Eugenia apresentam baixa longevidade natural (VON BÜLOW; CARMONA; VAZ PARENTE, 1994; GENTIL; FERREIRA, 1999).

Por apresentar vasta utilidade econômica e importância ecológica no bioma da Mata Atlântica e ainda ter sua propagação sexuada dificultada, o desenvolvimento de vias alternativas de multiplicação de uvaieira é de grande importância. Neste sentido, a cultura de tecidos de plantas, mais precisamente a micropropagação, surge como técnica eficiente na propagação clonal in vitro da espécie.

As citocininas constituem a classe de reguladores de crescimento mais utilizada na fase de multiplicação da micropropagação, pelo seu efeito na quebra da dominância apical e na indução da proliferação de gemas axilares. Das citocininas comercialmente disponíveis, o BAP (6-benzilaminopurina) é a que, em geral, apresenta melhores resultados in vitro para promover a multiplicação de diversas espécies, sendo utilizada em aproximadamente $60 \%$ dos meios de cultivo (GRATTAPAGLIA; MACHADO, 1998). Na fase de enraizamento, a maioria dos trabalhos de indução de raízes adventícias em espécies lenhosas envolve tratamentos com auxinas exógenas, tais como o ácido indolbutírico (AIB) e o ácido naftalenoacético (ANA) (ASSIS; TEIXEIRA, 1998).

Objetivou-se com este trabalho avaliar a influência dos reguladores de crescimento BAP e AIB na micropropagação de uvaieira (Eugenia pyriformis Cambess). 


\section{MATERIAL E MÉTODOS}

Segmentos caulinares de uvaieira, contendo até duas gemas laterais, foram retirados de plântulas obtidas da germinação in vitro e inoculados em meio de cultura WPM (LLOYD; McCOWN, 1980), suplementado com diferentes concentrações de BAP $\left(0,0 ; 1,0 ; 2,0 ; 3,0 ; 4,0\right.$ e 5,0 $\left.\mathrm{mg} \mathrm{L}^{-1}\right), 1,5 \mathrm{~g}$ $\mathrm{L}^{-1}$ de carvão ativado, $30 \mathrm{~g} \mathrm{~L}^{-1}$ de sacarose e solidificado com $0,7 \mathrm{~g} \mathrm{~L}^{-1} \mathrm{de}$ ágar. $\mathrm{O} \mathrm{pH}$ do meio de cultura foi ajustado para 5,7 , antes da autoclavagem a $120^{\circ} \mathrm{C}$, durante 20 minutos.

Após a inoculação, os segmentos foram transferidos para sala de crescimento sob irradiância de $36 \mathrm{mmol} \mathrm{m}^{-2} \mathrm{~s}^{-1}$, fotoperíodo de 16 horas e temperatura de $25 \pm 2^{\circ} \mathrm{C}$. Foram avaliados o número médio de brotos, folhas e gemas por explante e o comprimento da maior brotação, aos 60 dias de cultivo.

Brotações obtidas do cultivo in vitro foram transferidas para meio de cultura WPM na ausência de reguladores de crescimento, contendo $30 \mathrm{~g} \mathrm{~L}^{-1}$ de sacarose, $0,5 \mathrm{~g} \mathrm{~L}^{-1}$ de carvão ativado e solidificado com $7 \mathrm{~g} \mathrm{~L}^{-1}$ de ágar. $\mathrm{O} \mathrm{pH}$ foi ajustado para 5,7 antes da autoclavagem a $120^{\circ} \mathrm{C}$, durante 20 minutos. Após a inoculação, os explantes foram mantidos em sala de crescimento a $25 \pm 2^{\circ} \mathrm{C}$ e na presença de luz, por um período de 15 dias. Decorrido esse período, as brotações, com aproximadamente $1,5 \mathrm{~cm}$, foram transferidas para meio WPM, contendo diferentes concentrações de AIB (0,0; 1,0; 2,0; 3,0 e 4,0 $\left.\mathrm{mg} \mathrm{L}^{-1}\right), 30 \mathrm{~g} \mathrm{~L}^{-1}$ de sacarose, 7,0 $\mathrm{g} \mathrm{L}^{-1}$ de ágar e $0,5 \mathrm{~g} \mathrm{~L}^{-1}$ de carvão ativado. Após 40 dias foram avaliados a porcentagem de enraizamento nos diferentes tratamentos, bem como o número de raízes e o comprimento da maior raiz.

As plântulas de uvaieira oriundas do enraizamento in vitro, com 40 dias de idade, foram transferidas diretamente, ou após passarem por um período de 7 dias de pré-aclimatização (com abertura

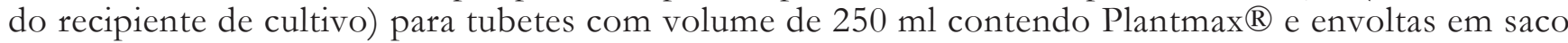
plástico transparente para a manutenção da umidade relativa no ambiente. A bandeja com os tubetes foi mantida em sala de crescimento à temperatura controlada de $25 \pm 2{ }^{\circ} \mathrm{C}$ e irradiância de fótons de 67 $\mathrm{mm} \mathrm{m}^{-2} \mathrm{~s}^{-1}$. Gradativamente, as sacolas de polietileno transparente foram sendo perfuradas até sua total remoção aos 30 dias, quando avaliou-se a porcentagem de sobrevivência nos tratamentos.

O delineamento experimental utilizado para todos os experimentos foi inteiramente casualizado. Para dados qualitativos, utilizou-se o Teste de Tukey e para dados quantitativos utilizouse regressão polinomial, ambos a 5\% de probabilidade.

\section{RESULTADOS E DISCUSSÃO}

Não foram verificadas diferenças significativas para o número médio de brotos formados quando os explantes caulinares de uvaieira foram submetidos às diferentes concentrações de BAP testadas. Houve formação de brotações em todos os tratamentos testados, mesmo na ausência do regulador de crescimento. Entre as concentrações de BAP testadas, observou-se que, para o número médio de brotos, os tratamentos que se destacaram foram aqueles em que se utilizou 1,0 e 4,0 $\mathrm{mg} \mathrm{L}^{-1}$ do regulador. Recomenda-se para essa espécie, o uso de 1,0 $\mathrm{mg} \mathrm{L}^{-1}$ de BAP para a indução de brotações, uma vez que esta concentração se mostrou eficiente, produzindo 2 brotações por explante.

Diferenças significativas também não foram observadas para o número de gemas, comprimento de brotações e número de folhas. No entanto, a concentração de $1,0 \mathrm{mg} \mathrm{L}^{-1}$ de BAP apresentou os maiores valores: 7,0 gemas por explante, $1,14 \mathrm{~cm}$ de comprimento para a maior brotação e 13,7 folhas por explante, respectivamente.

Oliveira et al. (2003) concluíram que a cinetina foi mais eficiente que o BAP na multiplicação in vitro de Tabernaemontana fuchsiaefolia L., enquanto que Carvalho, Carvalho e Otoni (2005) verificaram a melhor multiplicação in vitro de urucum na presença de zeatina e ácido naftalenoacético (Bixa orellana L.).

Para a multiplicação de guaco (Mikania glomerata Spreng) in vitro, a concentração de $1,0 \mathrm{mg}$ $\mathrm{L}^{-1}$ de BAP, na ausência de AIA, é suficiente para a emissão de maior número médio de gemas por explante (DINIZ et al., 2006).

A análise estatística das diferentes concentrações de AIB testadas mostrou a não significância dos tratamentos para o número de raízes. Foi observada formação de raízes em todas as concentrações testadas, mesmo na ausência do regulador de crescimento (10\% de enraizamento). A maior porcentagem

Rev. Acad., Ciênc. Agrár. Ambient., Curitiba, v. 6, n. 2, p. 223-228, abr./jun. 2008 
de enraizamento $(60 \%)$ foi verificada no tratamento contendo $1,0 \mathrm{mg} \mathrm{L}^{-1}$ de AIB, seguido do tratamento contendo 2,0 $\mathrm{mg} \mathrm{L}^{-1}$ de AIB (50\%) e das concentrações de 3,0 e 4,0 $\mathrm{mg} \mathrm{L}^{-1}$ de AIB (30 e 20\%, respectivamente). As maiores médias quanto à variável de número de raízes foram observadas na presença de 1,0 e 2,0 $\mathrm{mg} \mathrm{L}^{-1}$ de AIB, sendo igual a 1,0 em ambos os tratamentos (Figura 1).

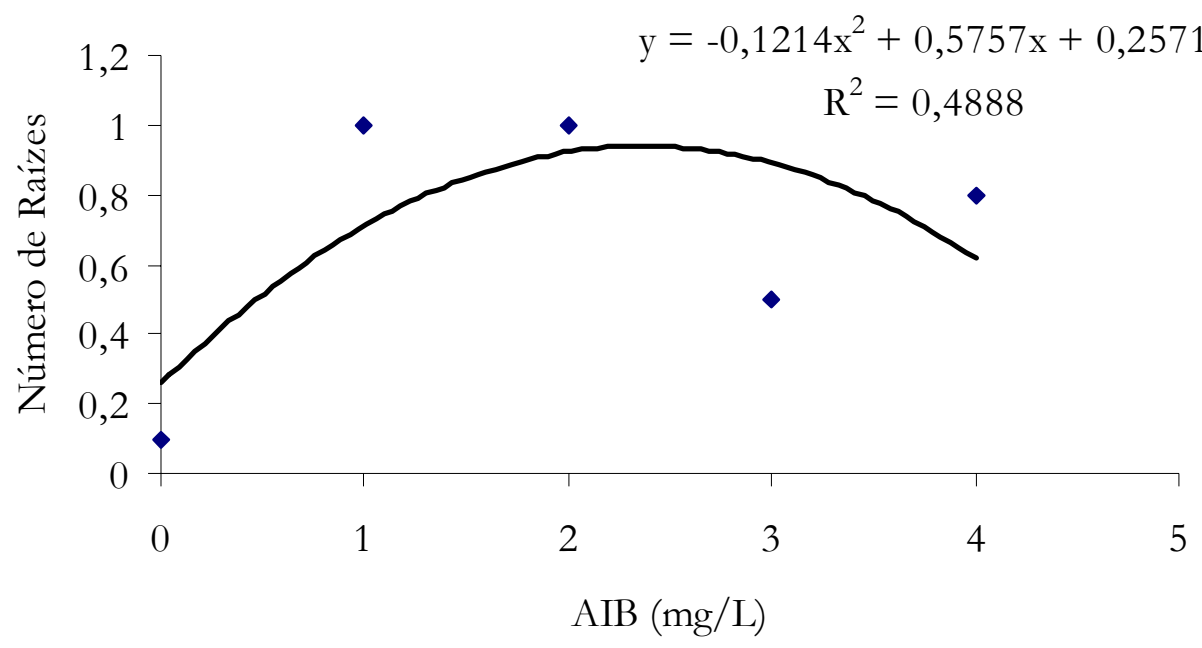

FIGURA 1 - Número de raízes formadas em brotações de uvaieira inoculadas em meio de cultura WPM contendo diferentes concentrações de AIB

Figure 1 - Number of roots formed in shoots of "uvaieira" inoculated in vitro WPM containing various concentrations of $A I B$

Carvalho, Carvalho e Otoni (2005) também verificaram o enraizamento de urucum (Bixa orellana L.) com a utilização de AIB. Segundo Santos et al. (2006), o uso de AIB, na concentração de 3,0 $\mathrm{mg} \mathrm{L}^{-1}$ e carvão ativado favoreceu a indução e o desenvolvimento de raízes em brotações de pequizeiro (Caryocar brasiliense Camb.).

A análise da variável de comprimento da maior raiz formada também se mostrou estatisticamente não significativa nos testes realizados. Os resultados obtidos podem ser observados na Figura 2.

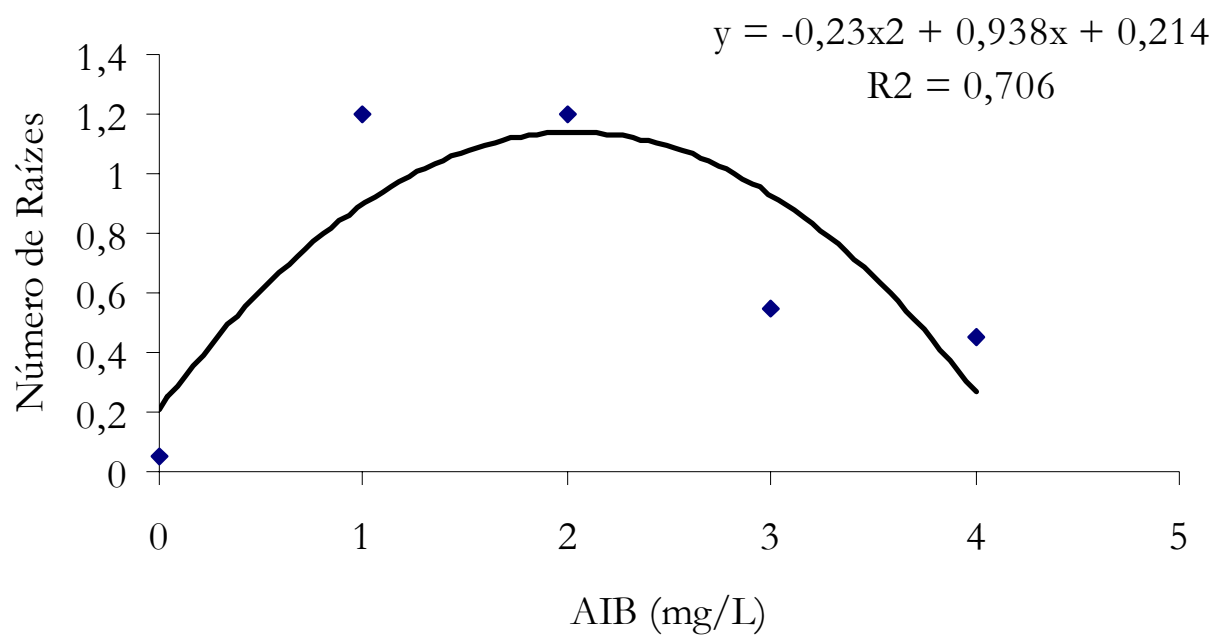

FIGURA 2 - Comprimento da maior raiz formada em brotações de uvaieira inoculadas em meio de cultura WPM contendo diferentes concentrações de AIB

Figure 2 - Length of higher root formed in shoots of "uvaieira" inoculated in vitro WPM containing various concentrations of $A I B$ 
Apesar da não significância dos tratamentos, os maiores comprimentos de raiz foram observados nos tratamentos contendo $1,0 \mathrm{mg} \mathrm{L}^{-1}$ e 2,0 $\mathrm{mg} \mathrm{L}^{-1}$ de AIB sendo, em ambos, de 1,23 cm.

A proporção de plântulas de uvaieira sobreviventes foi similar nos dois tratamentos, onde a pré-aclimatização apresentou $85 \%$ de sobrevivência e a aclimatização direta $69 \%$. Não foram observadas diferenças significativas, considerando-se um nível de significância fixado em 5\%.

A maior percentagem de sobrevivência das plântulas pré-aclimatizadas em relação às diretamente submetidas à fase de aclimatização, mesmo não havendo diferenças significativas entre os tratamentos, pode ser justificada pelo maior tempo de adaptação às novas condições de cultivo que, provavelmente, conferiram a essas plântulas melhores condições de tolerar o estresse causado pela transferência para as novas condições. Ziv (1996) relata que, quando os recipientes que continham plântulas de craveiro foram abertos e a umidade relativa mantida a 50\%-70\%, houve aumento no desenvolvimento de cera epicuticular e, após nove dias de abertura dos recipientes, a taxa de sobrevivência aumentou de 75\% para 90\%. Segundo Díaz-Pérez, Sutter e Shackel (1995), durante o processo de aclimatização ocorre a conversão da condição heterotrófica para autotrófica e um gradual retorno às características naturais da planta. As novas folhas formadas durante este processo já apresentam características intermediárias entre aquelas apresentadas in vitro e ex vitro, com mudanças na morfologia, redução na condutância estomática, incremento no conteúdo de clorofila e maior eficiência na carboxilação.

A abertura parcial do saco plástico envoltório dos tubetes também demonstrou ser importante na aclimatização de plântulas de uvaieira, uma vez que também favoreceu a percentagem de sobrevivência.

\section{CONCLUSÕES}

A concentração de $1,0 \mathrm{mg} \mathrm{L}^{-1} \mathrm{BAP}$ proporciona o maior número médio de brotações, folhas e gemas por explante, além do maior comprimento da brotação;

O regulador de crescimento AIB, na concentração de $1,0 \mathrm{mg} \mathrm{L}^{-1}$ produz a maior porcentagem de formação de raízes em brotações de uvaieira originadas in vitro;

O período de pré-aclimatização em sala de crescimento aumenta a proporção de sobrevivência de plântulas de uvaieira.

\section{REFERÊNCIAS}

ASSIS, T. F.; TEIXEIRA, S. L. Enraizamento de plantas lenhosas. In: TORRES, A. C.; CALDAS, L. S.; BUSO, J. A. Cultura de tecidos e transformação genética de plantas. Brasília: EmbrapaSPI; Embrapa-CNPH, 1998. v. 1, p. 261-296.

CARVALHO, J. F. R. P.; CARVALHO, C. R.; OTONI, W. C. Regeneração in vitro de urucum (Bixa orellana L.) a partir de diferentes tipos de explantes. Revista Árvore, Viçosa, v. 29, n. 6, p. 887-895, 2005. Disponível em: <http://www.scielo.br/scielo.php?script=sci_arttext\&pid=S010067622005000600007\&lng=pt\&nrm=iso >. Acesso em: 02 mar. 2007.

DÍAZ-PÉREZ, J. C.; SUTTER, E. G.; SHACKEL, K. A. Acclimatization and subsequent gasexchange, water relations, survival and growth of microcultured apple plantlets after transplanting them in soil. Physiologia Plantarum, Copenhagen, v. 95, n. 2, p. 225-232, 1995.

DINIZ, J. D. N. et al. Multiplicação e enraizamento in vitro do guaco. Revista Ciência Agronômica, Fortaleza, v. 37, n. 1, p. 59-64, 2006.

GENTIL, D. F. O.; FERREIRA, S. A. N. Viabilidade e superação da dormência em sementes de araçá-boi (Eugenia stipitata ssp. sororia). Acta Amazonica, Manaus, v. 29, n. 1, p. 21-31. 1999. 
GRATTAPAGLIA, D.; MACHADO, M. A. Micropropagação. In: TORRES, A. C.; CALDAS, L. S.; BUSO, J. A. Cultura de tecidos e transformação genética de plantas. Brasília, DF: EmbrapaSPI; Embrapa-CNPH, 1998. v. 1, p. 183-260.

LLOYD, G.; McCOWN, B. Commercially: feasible micropropagation of mountain laurel, Kalmia latifolia, by use of shoot tip culture. International Plant Propagators Society Proceedings, Washington, v. 30, p. 421-427, 1980.

LORENZI, H. Árvores brasileiras: manual de identificação e cultivo de plantas arbóreas nativas do Brasil. Nova Odessa: Plantarum, 2000. v. 1.

MATTOS, J. R. Estudo pomológico dos frutos indígenas do Rio Grande do Sul. Porto Alegre, RS: SIPA, 1956. (Fascículo, 2).

OLIVEIRA, A. J. B. et al. Multiplicação in vitro de Tabernaemontana fuchsiaefolia L. (Apocynaceae). Revista Árvore, Viçosa, v. 27, n. 4, p. 421-425, 2003. Disponível em: <http://www.scielo.br/ scielo.php?script $=$ sci_arttext\&pid $=$ S0100-67622003000400001\&lng $=$ pt\&nrm $=$ iso $>$. Acesso em: 02 mar. 2007.

SANTOS, B. R. et al. Micropropagação de pequizeiro (Caryocar brasiliense CAMB.). Revista Brasileira de Fruticultura, Pelotas, v. 28, p. 293-296, 2006.

SILVA, C. V. et al. Seed germination of "uvaia" (Eugenia pyriformis Cambess. - Myrtaceae) after cutting. Revista Brasileira Botânica, São Paulo, v. 26, n. 2, p. 213-221. 2003. Disponível em: $<$ http:/ / ww w.scielo.br/scielo.php? script=sci_arttext\&pid=S010084042003000200009\&lng=en\&nrm=iso>. Acesso em: 21 mar. $200 \overline{7}$.

VON BÜLOW, J. F. W.; CARMONA, R.; VAZ PARENTE, T. Armazenamento e tratamento de sementes de pitanga-vermelha-do-cerrado (Eugenia calycina). Pesquisa Agropecuária Brasileira, Brasília, v. 29, p. 961-970, 1994.

ZIV, M. In vitro hardening and acclimatization of tissue culture plants. In: WITHERS, L. A.; ALDERSON, P. G. (Ed.). Plant tissue culture and its agricultural applications. London: Butterworths, 1996. p. 187-196. 